\title{
Health-risk behavior differences between boarding and non-resident students: Brazilian adolescent National School Health Survey
}

Matias Noll ${ }^{1,2^{*}}$ (D), Priscilla Rayanne e Silva Noll ${ }^{1,3}$, Carlos Leandro Tiggemann ${ }^{4}$, Daniela Costa Custodio ${ }^{1}$ and Erika Aparecida Silveira ${ }^{2}$

\begin{abstract}
Background: Studies that evaluated health-risk behaviors with boarding students are scarce. There are no studies with representative samples among adolescents residing in educational institutions in Latin America. To better assess the role of resident status on such behaviors, this study aimed to compare health-risk behaviors between boarding and non-resident students assessed by the Brazilian National Adolescent School Health Survey (PeNSE).

Methods: A cross-sectional study was conducted using the 2015 PeNSE database. A sample of 101,788 students (aged 11-19years) from both public and private schools throughout all the Brazilian states completed the survey. A self-administered questionnaire was used to evaluate multiple health-related behaviors (sociodemographic characteristics; sexual behavior; cigarette use; drug use; and alcohol use). Poisson regression model-based analyses were performed and the effects measured through the prevalence ratio (PR) and its 95\% confidence interval (Cl).

Results: Boarding residents reported more health-risk behaviors than non-residents: previous sexual intercourse (PR $1.17,1.10-1.25)$, smoking experience (PR 1.12, 1.03-1.21), monthly smoking frequency (PR 1.68, 1.42-1.99), monthly alcohol intake (PR 2.12, 1.79-2.50), inebriation (PR 1.51, 1.35-1.71), drug use experience (PR 1.23, 1.10-1.38), and monthly drug use frequency (PR 1.59, 1.31-1.94).

Conclusions: Boarding residents reported more health-risk behaviors than did non-residents. The results provide insights into an under-researched subject, helping to highlight potential points of intervention for supporting public health programs within the boarding-school student population.
\end{abstract}

Keywords: Adolescent, Health, Boarding school, Survey, Sexual intercourse, Smoking, Drinking alcohol drinking, Drugs

\section{Background}

A high prevalence of several health-risk behaviors is common among adolescent students. This age, between 10 and 19 years [1], is an intense transition phase associated with maturation [2] and several unhealthy behaviors, such as smoking, drinking, illicit drug use, and risky sexual behaviors, begin during this time period [2-4]. Although there is no uniform definition of

\footnotetext{
* Correspondence: matiasnoll@yahoo.com.br; matias.noll@ifgoiano.edu.br ${ }^{1}$ Instituto Federal Goiano (IF Goiano), Goiás, Brazil

${ }^{2}$ Postgraduate Program in Health Sciences, Faculdade de Medicina, Universidade Federal de Goiás (UFG), Goiás, Brazil

Full list of author information is available at the end of the article
}

health-risk behavior worldwide, it is generally considered as behaviors that potentially negatively affect health [5-7], such as substance use, unsafe sexual behavior (e.g., in regard to condom use and number of sexual partners), eating disorders, and antisocial, violent, or suicidal behaviors, among others [8]. Healthrisk conditions may be increased by inequalities, which are intensified in socioeconomically weak environments [2, 9-11]. Related to this, students' living conditions (i.e., school residency environments) can also influence risky health behaviors [12-16].

Health studies with students residing in educational institutions (EI) are scarce $[12,13,17,18]$. Initial evidence

(c) The Author(s). 2020 Open Access This article is distributed under the terms of the Creative Commons Attribution 4.0 International License (http://creativecommons.org/licenses/by/4.0/), which permits unrestricted use, distribution, and reproduction in any medium, provided you give appropriate credit to the original author(s) and the source, provide a link to the Creative Commons license, and indicate if changes were made. The Creative Commons Public Domain Dedication waiver (http://creativecommons.org/publicdomain/zero/1.0/) applies to the data made available in this article, unless otherwise stated. 
suggests increased alcohol consumption, tobacco and marijuana use, risky sexual behaviors, sedentarism, and poor eating habits among students in residential housing [16, 19-21]. Furthermore, these behaviors tend to increase the longer the student has lived in residential housing [16, 22]. One key explanation could be the feelings of independence from, and lack of accountability toward, their family that students perceive when living away from home [14].

The present study focuses on address the dearth of studies on health-risk behaviors among students residing in EIs within developing Latin American countries, and covered risky sexual behavior and substance use. Only one study with a small, non-representative sample has assessed health behavior risks among adolescents residing in an EI within Latin America [12]. The study revealed that resident Brazilian students reported high levels of unhealthy behaviors, including cigarette smoking, alcohol use, and risky sexual behaviors, which were aggravated by fragile socioeconomic conditions. To better assess the role of resident status on such behaviors, we analyzed data from a national cross-sectional representative sample of students throughout Brazil. Our results could help contribute to planning health promotion and disease prevention activities for addressing problematic health behaviors within this at-risk student sample. Thus, the present study aimed to compare health-risk behaviors between boarding and nonresident students assessed by the Brazilian National School Health Survey (PeNSE).

\section{Methods}

\section{Overview of research project}

This study used data from the 2015 PeNSE [23]. The survey assesses students aged 11-19 classified as 9th graders from both public and private schools throughout Brazil.

The sample size calculations were based on parameters for all 26 states and the Federal District, including inside each state, the capital, and other municipalities with smaller populations. Brazil is conventionally divided into five regions (North, Northeast, Southeast, South, and Midwest) [24]. Samples across capitals and municipalities were random and equiprobabilistic. The following parameters were used for deriving the sample: maximum error of $3 \%$, confidence level of $95 \%$, and prevalence of 0.5 . All students in the sample classes were invited to respond to the survey questionnaire. Further information on sampling procedures may be found in Oliveira et al. [24].

\section{Participants}

A total of 120,122 students, attending 4159 classes across 3040 schools, were included in the sample in 2015. From all students enrolled, 15.3\% of regular students did not attend the class, did not agree to participate, or did not fully complete the questionnaire. A total of 101,788 students completed the survey questionnaire on the sampling day.

\section{Ethical considerations}

The PeNSE acquired consent from the heads of the schools and all students who voluntarily agreed to participate provided written informed consent. Students were told that they could leave the study at any time and could refuse to participate in any of the procedures. Anonymity and privacy were fully guaranteed to the participants. The PeNSE was approved by the National Commission on Ethics in Research of the National Health Council, which regulates and approves health research involving human participants (no. 1,006,467) $[23,24]$.

\section{Data collection and data analysis}

Data collection was performed using smartphones distributed to students, who were in class on the day of the interview, by an IBGE technician. The technician explained how to use the device [24].

The explanatory variable evaluated was:

- Boarding schools: characterized as regulated educational institutions [25], with students residing at the school during the academic year [18].

The health-risk behavior outcome variables were:

- Sexual behavior (prior sexual intercourse; age of first sexual intercourse; number of previous sexual partners; use of condoms during their last instance of sexual intercourse);

- Substance use: tobacco use (smoked at least one prior time; frequency of smoking over the past 30 days); alcohol use (experienced drinking at least once; frequency of drinking over the past 30 days, experienced getting drunk at least once); illegal drug use [marijuana, cocaine, crack] (used at least one prior time; frequency of use over the past 30 days);

The adjustment variables included:

- Sociodemographic characteristics (municipality [capital city or non-capital city], school [public or private], class shift [full-time or part-time], sex, age, region, mother's educational history).

Data were analyzed using descriptive statistics and Chi-Square tests (bivariate analysis) to compare frequencies of health-risk behaviors between students residing in EIs (boarding students) and non-residents. Poisson 
regression models were also analyzed, with the following dummy-coded outcome variables: prior sexual intercourse ( 0 , no; 1 , yes), age of first sexual intercourse $(0,>$ 13 years old; $1, \leq 12$ years old), number of sexual partners $(0,<2 ; 1, \geq 2)$; use of condoms during the last instance of sexual intercourse ( 0 , yes; 1 , no), experience smoking ( 0 , no; 1 , yes), smoked in the last 30 days $(0,<$ $3 ; 1, \geq 3$ days), experience drinking ( 0 , no; 1 , yes), drinking during the last 30 days $(0,<10,1, \geq 10$ days), experience getting drunk $(0,<3,1, \geq 3$ days), drug use $(0$, no; 1 , yes), and drug use during the past 30 days $(0,<3,1, \geq$ 3 days).

Poisson regression model-based analysis was performed and the effect measure was the prevalence ratio (PR) with and its 95\% confidence interval [26]. Adjusted Poisson regression was performed and the sociodemographic variables were considered confounding variables: municipality, school, class shift, sex, age, region of Brazil, and mother's schooling $(\alpha=.05)$. Methodological and statistical studies support the inclusion of variables with theoretical grounds in statistical analyses [26-28]. Statistical analyses were performed using SPSS 20.0 (IBM, Armonk, NY, USA).

\section{Results}

Of the 101,788 students who completed the survey, $3.8 \%$ $(n=3846)$ resided in an EI and $96.2 \%(n=97,942)$ were non-residents. Students attending boarding schools are more prevalent in the north and northeast regions $(p<.001)$, non-capital areas $(p<.001)$, and public schools $(p<.001)$. In addition, boarding students attend more schools with full time classes $(p<.001)$ their mothers' had higher education level categorized more frequently as none or elementary school $(p<.001)$ as compared to non-resident students (Table 1).

Boarding students reported a higher prevalence of sexual intercourse $(p<.001)$, more sexual partners $(p<.001)$, more smoking experience, and higher monthly smoking frequency $(p<.001)$, higher alcohol intake in the past month, as well as drinking to excess $(p<.001)$, more drug use experience, and higher monthly drug use $(p<.001)$ (Table 2).

The results of the Poisson regression analyses are presented in Tables 3 and 4. The adjusted PR results indicated that boarding students had more sexual intercourse (PR 1.17, 1.10-1.25), higher experience smoking (PR 1.12, 1.03-1.21), higher monthly smoking frequency (PR 1.68, 1.42-1.99), higher monthly alcohol consumption (PR 2.12, 1.79-2.50), more frequent occasions of getting drunk (PR 1.51, 1.35-1.71), higher previous drug use (PR 1.23, 1.10-1.38), and higher monthly drug use (PR 1.59, 1.31-1.94) as compared to nonresident students.

\section{Discussion}

Boarding students reported greater frequency of healthrisk behaviors as compared to non-residents, regarding risky sexual behavior, smoking, and alcohol and drug consumption. The present results are relevant given the lack of research on health-risk behaviors among adolescent students residing in EIs. Thus, our findings could have implications for targeted health promotion/prevention efforts within this population.

One notable aspect of the present study was the relatively small sample of 9th grade boarding students (less than $4 \%$ of the total sample). This is not too surprising given that Brazil has relatively few boarding schools in comparison to other countries such as the United States, Australia, United Kingdom [17, 18], Israel [14], and Turkey [29]. Despite the greater presence of boarding schools in these countries, studies on health-risk behaviors in boarding schools are also relatively sparse worldwide. For instance, in Israel, $10 \%$ of students live in boarding schools; yet, very few studies have examined mental health and well-being within this population [14].

Our results revealed that boarding students engaged in more sexual intercourses than did non-residents. Similar findings have been observed in college students in the United States [19]. The boarding school environment provides greater freedom and, consequently, perhaps more permissive sexual attitudes [22]. Interestingly, condom use was comparable between the boarding and non-resident students in the present sample (approximately 69\%). Condom use is a key component of sexual health, as condom use is associated with lower incidence of sexually transmitted diseases [2]. Condom use in the context of multiple sexual partners often differs between countries; however, worldwide use is often below 50\% among adolescents [2]. According to Spring, Moller, and Coons [3], 34\% of sexually active high school students reported not using a condom during their most recent sexual encounter.

Boarding residents were also more likely to smoke than non-residents. In terms of percentages, $23.7 \%$ of boarding students reported some smoking experience, with $12.8 \%$ smoking on 10 or more days in the past month. This was significantly higher than the $6 \%$ of non-residents who smoked 10 or more days, and is in keeping with results from prior studies [9,30], although $18 \%$ of adolescents aged 15 years old in Europe report smoking at least once a week [9]. According to Agmon, Zlotnick, and Finkelstein [14], smoking is cited as a normative behavior within boarding schools in Israel, which could be related to adolescents' difficulties in avoiding all enticing risky behaviors [31]. However, in Turkey, smoking behavior was lowest and similar between boarding students and non-residents $(1.9 \% ; 2.2 \%)$ [29]. 
Table 1 Demographic characteristics of the sample from the Brazilian National School Health Survey (PeNSE), Brazil

\begin{tabular}{|c|c|c|c|c|}
\hline Variables & Total N (\%) & Boarding Students \% & Non-residents \% & Chi-Square $p$-value \\
\hline \multicolumn{5}{|l|}{ Region $(n=101,788)$} \\
\hline North & $23,857(23.4)$ & 27.4 & 23.3 & \multirow[t]{5}{*}{$<.001$} \\
\hline Northeast & $36,232(35.6)$ & 34.9 & 35.6 & \\
\hline Southeast & $17,732(17.4)$ & 14.8 & 17.5 & \\
\hline Midwest & $14,144(13.9)$ & 15.6 & 13.8 & \\
\hline South & $9823(9.7)$ & 7.3 & 9.7 & \\
\hline \multicolumn{5}{|l|}{ Municipality $(n=101,788)$} \\
\hline Non-capital & $50,725(49.8)$ & 55,5 & 49,6 & \multirow[t]{2}{*}{$<.001$} \\
\hline Capital & $51,063(50.2)$ & 44,5 & 50,4 & \\
\hline \multicolumn{5}{|l|}{ School $(n=101,788)$} \\
\hline Public & $80,905(79.5)$ & 87.5 & 79.2 & \multirow[t]{2}{*}{$<.001$} \\
\hline Private & $20,883(20.5)$ & 12.5 & 20.8 & \\
\hline \multicolumn{5}{|l|}{ Class shift $(n=101,378)$} \\
\hline Part-time & $78,587(77.5)$ & 38.9 & 79 & \multirow[t]{2}{*}{$<.001$} \\
\hline Full-time ( $\geq 7 \mathrm{~h}$ per day) & $22,791(22.5)$ & 61.1 & 21 & \\
\hline \multicolumn{5}{|c|}{ Mother's education $(n=76,477)$} \\
\hline None & $5508(7.2)$ & 17.5 & 6.8 & \multirow[t]{4}{*}{$<.001$} \\
\hline Elementary School ${ }^{a}$ & $24,181(31.6)$ & 39.8 & 31.3 & \\
\hline High School ${ }^{a}$ & $24,138(31.6)$ & 24.2 & 31.8 & \\
\hline Graduate $^{a}$ & $22,650(29.6)$ & 18.6 & 30 & \\
\hline \multicolumn{5}{|l|}{ Age (years) $(n=101,788)$} \\
\hline $11-13$ & $17,205(16.9)$ & 9.8 & 17.2 & \multirow[t]{4}{*}{$<.001$} \\
\hline 14 & $51,480(50.6)$ & 39.5 & 51 & \\
\hline 15 & $20,802(20.4)$ & 27 & 20.2 & \\
\hline $16-19$ & $12,301(12.1)$ & 23.6 & 11.6 & \\
\hline \multicolumn{5}{|l|}{$\operatorname{Sex}(n=101,788)$} \\
\hline Male & $49,151(48.3)$ & 58.7 & 47.9 & \multirow[t]{2}{*}{$<.001$} \\
\hline Female & $52,637(51.7)$ & 41.3 & 52.1 & \\
\hline
\end{tabular}

${ }^{a}$ Complete and incomplete educational level

Alcohol consumption, both in terms of frequency during the last 30 days and getting drunk, was also more prevalent among boarding students compared with nonresidents. Specifically, $11.3 \%$ of boarding students reported drinking on at least 10 days during the last month, and $20.5 \%$ reported getting drunk at least three or more times in their lifetime. This result corroborates prior data from a study that evaluated adolescents in high school [12] and those transitioning from high school to college [22]. Although it is important to highlight that in Brazil, the sale of alcoholic drinks is prohibited to those under 18 years old, the students have substantial access to these products [32, 33], just like elsewhere in the world [34]. Furthermore, in Brazil, drinking alcohol is permitted socially, especially for men, because it is related to male power [32, 33].
The 2012 PeNSE [35] reported that 7.3\% of adolescents used illicit drugs at least once in their life, and this number increased to 9\% in 2015 [36]. In Israel, approximately $75 \%$ of students had never smoked marijuana, which was the only drug evaluated in that study [14]. Drug use has been associated with risky behaviors during the transition from high school to college, but not with type of high school residence [22], even when singled out as a common practice within boarding schools [31]. Illicit drug use is a key public-health problem with deep psychological and social consequences, especially for children and adolescents [2]. Being away from one's family while at boarding school may lead to drug and alcohol consumption for similar reasons that students engage in risky sexual behaviors $[3,19,20]$. It is important to note that smoking, drinking, and illicit drug use 
Table 2 Health-risk behavior comparisons between boarding and non-resident students in Educational Institutions from the Brazilian National School Health Survey (PeNSE), Brazil

\begin{tabular}{|c|c|c|c|c|}
\hline Variables $^{\text {a }}$ & Total N (\%) & Boarding Students \% & Non-residents \% & Chi-Square $p$-value \\
\hline \multicolumn{5}{|l|}{ Sexual Behavior } \\
\hline \multicolumn{5}{|c|}{ Prior sexual intercourse $(n=101,314)$} \\
\hline No & $72,815(71.9)$ & 57.9 & 72.4 & \multirow[t]{2}{*}{$<.001$} \\
\hline Yes & $28,499(28.1)$ & 42.1 & 27.6 & \\
\hline \multicolumn{5}{|c|}{ Age of first sexual intercourse ${ }^{b}(n=28,271)$} \\
\hline$\leq 12$ years & $7382(26.1)$ & 29 & 25.9 & \multirow[t]{3}{*}{$<.001$} \\
\hline 13 and 14 years & $15,423(54.6)$ & 45.5 & 55.1 & \\
\hline$\geq 15$ years & $5466(19.3)$ & 25.5 & 19 & \\
\hline \multicolumn{5}{|c|}{ Number of sexual partners ${ }^{b}(n=28,327)$} \\
\hline 1 & $10,193(36)$ & 29.2 & 36.4 & \multirow[t]{3}{*}{$<.001$} \\
\hline 2 to 3 & $9143(32.2)$ & 31 & 32.3 & \\
\hline 4 or more & $8991(31.7)$ & 39.7 & 31.3 & \\
\hline \multicolumn{5}{|c|}{ Condom use during last sexual intercourse ${ }^{b}(n=27,335)$} \\
\hline Yes & $18,905(69.2)$ & 69.4 & 69.1 & \multirow[t]{2}{*}{.850} \\
\hline No & $8430(30.8)$ & 30.6 & 30.9 & \\
\hline \multicolumn{5}{|l|}{ Substance use } \\
\hline \multicolumn{5}{|c|}{ Experience smoking $(n=101,626)$} \\
\hline No & $82,945(81.6)$ & 76.3 & 81.8 & \multirow[t]{2}{*}{$<.001$} \\
\hline Yes & $18,681(18.4)$ & 23.7 & 18.2 & \\
\hline \multicolumn{5}{|c|}{ Smoked during the last 30 days ${ }^{b}(n=18,623)$} \\
\hline None & $13,216(71)$ & 56.6 & 71.7 & \multirow[t]{4}{*}{$<.001$} \\
\hline 1 to 2 days & $2878(15.5)$ & 21.2 & 15.2 & \\
\hline 3 to 9 & $1322(7.1)$ & 9.4 & 7 & \\
\hline 10 or more & $1207(6.5)$ & 12.8 & 6 & \\
\hline \multicolumn{5}{|c|}{ Experience drinking $(n=101,591)$} \\
\hline No & $48,998(51.8)$ & 48 & 48.2 & \multirow[t]{2}{*}{.785} \\
\hline Yes & $52,593(48.2)$ & 52 & 51.8 & \\
\hline \multicolumn{5}{|c|}{ Drinking during the last 30 days $^{b}(n=52,503)$} \\
\hline None & $30,355(57.8)$ & 49.5 & 58.1 & \multirow[t]{3}{*}{$<.001$} \\
\hline 1 to 9 days & $19,470(37.1)$ & 39.3 & 37 & \\
\hline 10 or more & $2678(5.1)$ & 11.3 & 4.9 & \\
\hline \multicolumn{5}{|c|}{ Experience getting drunk ${ }^{\mathrm{b}}(n=52,510)$} \\
\hline None & $32,292(61.5)$ & 52.4 & 61.9 & \multirow[t]{4}{*}{$<.001$} \\
\hline 1 to 2 days & $13,316(25.4)$ & 27.1 & 25.3 & \\
\hline 3 to 9 days & $4705(9)$ & 11 & 8.9 & \\
\hline 10 or more & $2192(4.2)$ & 9.5 & 4 & \\
\hline \multicolumn{5}{|c|}{ Previous drug use (marijuana, cocaine, crack) $(n=101,544)$} \\
\hline No & $92,906(91.5)$ & 87.9 & 91.6 & \multirow[t]{2}{*}{$<.001$} \\
\hline Yes & $8638(8.5)$ & 12.1 & 8.4 & \\
\hline \multicolumn{5}{|c|}{ Used drugs in the last 30 days ${ }^{\mathrm{b}}(n=8597)$} \\
\hline none & $4686(54.5)$ & 37.9 & 55.4 & \multirow[t]{4}{*}{$<.001$} \\
\hline 1 to 2 days & $1990(23.1)$ & 28.9 & 22.8 & \\
\hline 3 to 9 days & $1093(12.7)$ & 16.6 & 12.5 & \\
\hline 10 or more & $828(9.6)$ & 16.6 & 9.2 & \\
\hline
\end{tabular}

${ }^{a}$ For some variables, the totals are less than the total because of missing data; ${ }^{b}$ Only where applicable 


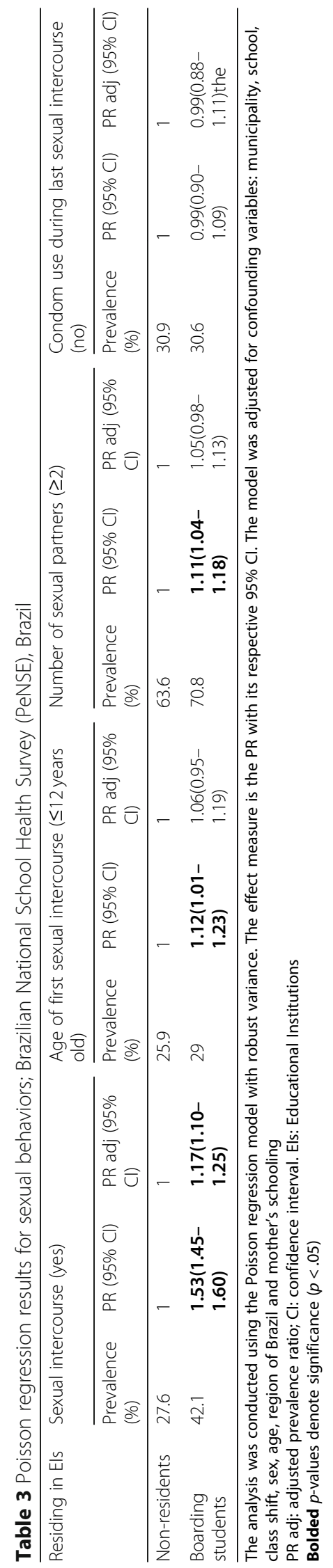




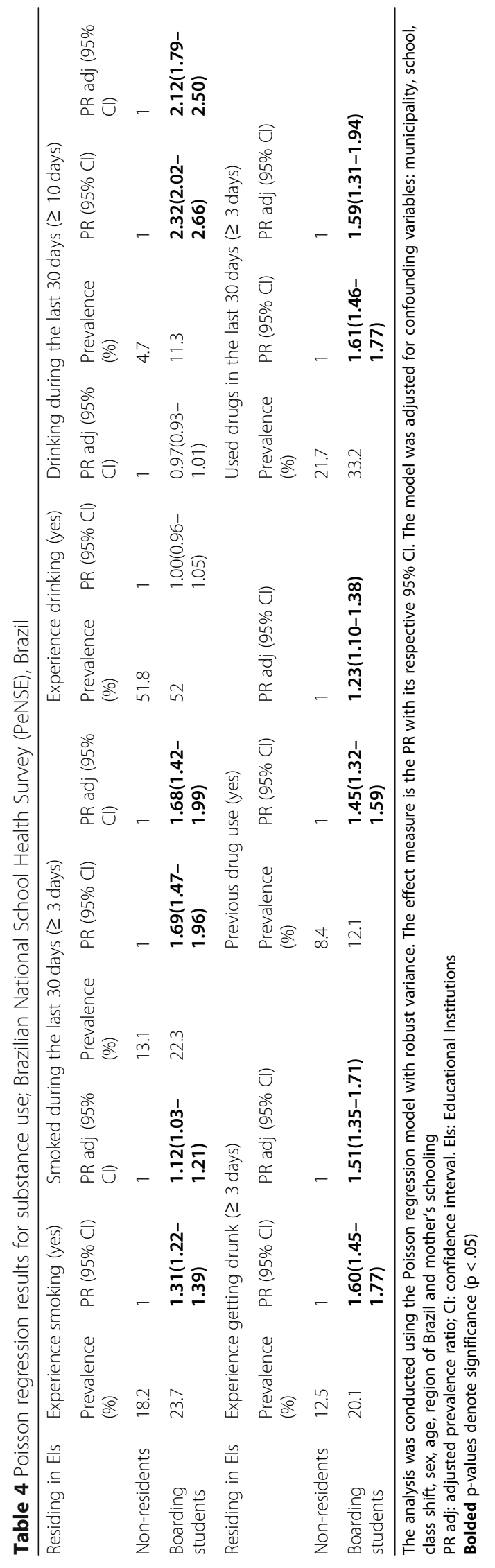


are associated with engaging in risky sexual behaviors [3, $9,37,38]$.

A few study limitations should be noted. First, given the cross-sectional nature of our design, we cannot make any causal inferences from our data; however, it highlights the relevant associations between health-risk behaviors in boarding students. Second, we cannot be certain that adolescents' self-reports truly reflect their actual behaviors. It should be noted that this kind of bias is inherent in all studies that analyze behavior attitudes. Due to potential demand characteristics when reporting, it is possible that we are underestimating or overestimating the actual behaviors. However, given the relatively large sample, it is likely that biases in reporting did not greatly influence our results.

Overall, higher rates of sexual intercourse, higher prevalence of smoking, and alcohol and drug consumption were reported as more prevalent among boarding students as compared to non-residents. It is possible that the greater independence and freedom experienced at this age is potentially problematic $[13,39]$. These data suggest that boarding students warrant greater emphasis on health risk screening and preventive counseling. The implication of the study findings is clear that the significant associations between boarding students and risky health behaviors should be considered in policies and guidelines. In this sense, more structured and healthy environments may be necessary for students who live at this kind of residence [13]. These students need more attention, advice, and health-promotion activities to lead them to responsibility and a conscientious use of their freedom. For instance, trained mentors could be provided to help hold the students more accountable [14]. It is also possible that helping students maintain closer contact with their family could help with health promotion. Finally, schools should develop health promotion activities, such as encouraging students to engage in more adaptive and productive behaviors (i.e., cultural activities and sports) to better assist students' maturation. Clearer policies and guidelines that can be applied on a daily basis will help create a safe and supportive environment for this student population $[18,25]$.

\section{Conclusions}

Boarding residents reported more health-risk behaviors than did non-residents. Our results provide insights into an under-researched subject, helping to highlight potential points of intervention for supporting public health programs within the boardingschool student population.

\section{Abbreviation}

PeNSE: Brazilian National School-Based Health Survey

\section{Acknowledgements}

The authors gratefully acknowledge support from the Instituto Federal Goiano and the FAPESP.

\section{Authors' contributions}

MN, PRSN, and EAS contributed to conception, study design, data acquisition, data analysis, data interpretation and drafting the manuscript CLT and DCC and EAS were involved in the analysis, data interpretation, critical revisions. All authors gave final approval and agree to be accountable for all aspects of work ensuring integrity and accuracy.

\section{Funding}

Not applicable.

\section{Availability of data and materials}

The datasets used and/or analysed during the current study are available from the corresponding author on request.

Ethics approval and consent to participate

Not applicable.

Consent for publication

Not applicable.

\section{Competing interests}

The authors declare that they have no competing interests.

\section{Author details}

${ }^{1}$ Instituto Federal Goiano (IF Goiano), Goiás, Brazil. ${ }^{2}$ Postgraduate Program in Health Sciences, Faculdade de Medicina, Universidade Federal de Goiás (UFG), Goiás, Brazil. ${ }^{3}$ Disciplina de Obstetrícia, Departamento de Obstetrícia e Ginecologia, Faculdade de Medicina, Universidade de São Paulo (FMUSP), Universidade de São Paulo, São Paulo, Brazil. ${ }^{4}$ Universidade do Vale do Taquari (UNIVATES), Rio Grande do Sul, Brazil.

Received: 27 October 2019 Accepted: 16 January 2020

Published online: 04 March 2020

\section{References}

1. World Health Organization. Adolescent Health. 2016.

2. Patton GC, Sawyer SM, Santelli JS, Ross DA, Afifi R, Nicholas B, et al. Our future: a lancet commission on adolescent health and wellbeing. Lancet. 2018;387:2423-78. https://doi.org/10.1016/S0140-6736(16)00579-1.Our.

3. Spring B, Moller AC, Coons MJ. Multiple health behaviours: overview and implications. J Public Health (Bangkok). 2012;34:i3-i10. https://doi.org/10. 1093/pubmed/fdr111.

4. Leatherdale ST, Rynard V. A cross-sectional examination of modifiable risk factors for chronic disease among a nationally representative sample of youth: are Canadian students graduating high school with a failing grade for health? BMC Public Health. 2013;13:569-77. https://doi.org/10.1186/14712458-13-569.

5. Kann L, McManus T, Harris WA, Shanklin SL, Flint KH, Queen B, et al. Youth Risk Behavior Surveillance — United States, 2017. MMWR Surveill Summ. 2018:67:1-114. https://doi.org/10.15585/mmwr.ss6708a1.

6. Guo L, Wang T, Wang W, Huang G, Xu Y, Lu C. Trends in health-risk behaviors among Chinese adolescents. Int J Environ Res Public Health. 2019; 16:1902. https://doi.org/10.3390/ijerph16111902.

7. Suris J-C, Michaud P-A, Akre C, Sawyer SM. Health risk behaviors in adolescents with chronic conditions. Pediatrics. 2008;122:e1113-8. https:// doi.org/10.1542/peds.2008-1479.

8. V I, E IC. Theories of adolescent risk-taking behavior. Handbook of Adolescent Health Risk Behavior. New York: Plenum; 1996. pp. 35-51.

9. Currie C, Zanotti C, Morgan A, Currie D, de Looze M, Roberts C, et al. Social determinants of health and well-being among young people. Health Behaviour in School-aged Children (HBSC) study: International report from the 2009/2010 survey. Copenhagen: WHO Reg Off Eur; 2012. p. 272.

10. Viner RM, Ozer EM, Denny S, Marmot M, Resnick M, Fatusi A, et al. Adolescence and the social determinants of health. Lancet Elsevier Ltd. 2012;379:1641-52. https://doi.org/10.1016/s0140-6736(12)60149-4.

11. Kumanyika SK. Five critical challenges for public health. Heal Educ Behav. 2014;41:5-6. https://doi.org/10.1177/1090198113511818. 
12. Noll PRES, Silveira NDA, Noll M, Barros PDS. High school students residing in educational public institutions: health-risk behaviors. PLoS One. 2016;11:114. https://doi.org/10.1371/journal.pone.0161652.

13. Pavletic AC, Dukes T, Greene JG, Taylor J, Gilpin LB. Health Services in Boarding School: an oasis of care, counseling, and comfort. J Sch Nurs. 2016:32:304-14. https://doi.org/10.1177/1059840516649234.

14. Agmon M, Zlotnick C, Finkelstein A. The relationship between mentoring on healthy behaviors and well-being among Israeli youth in boarding schools: a mixed-methods study. BMC Pediatr. 2015;15:11. https://doi.org/10.1186/ s12887-015-0327-6.

15. Papadaki A, Hondros GA, Scott J, Kapsokefalou M. Eating habits of University students living at, or away from home in Greece. Appetite. 2007;49:169-76. https://doi.org/10.1016/j.appet.2007.01.008

16. Simons-Morton B, Haynie D, Liu D, Chaurasia A, Li K, Hingson R. The effect of residence, school status, work status, and social influence on the prevalence of alcohol use among emerging adults. J Stud Alcohol Drugs. 2016:77:121-32. https://doi.org/10.15288/jsad.2016.77.121.

17. Martin AJ, Papworth B, Ginns P, Liem GAD. Boarding school, academic motivation and engagement, and psychological well-being: a large-scale investigation. Am Educ Res J. 2014;51:1007-49. https://doi.org/10.3102/ 0002831214532164.

18. Hodges J, Sheffield J, Ralph A. Home away from home? Boarding in Australian schools. Aust J Educ. 2013;57:32-47. https://doi.org/10.1177/ 0004944112472789.

19. Small M, Bailey-Davis L, Morgan N, Maggs J, Manuscript A, Activity P, et al. Changes in eating and physical Activity behaviors across seven semesters of college: living on or off campus matters. Heal Educ Behav. 2013;40:435-41. https://doi.org/10.1177/1090198112467801.

20. Schmied EA, Parada H, Horton LA, Madanat $H$, Ayala GX. Family Support Is Associated With Behavioral Strategies for Healthy Eating Among Latinas. Heal Educ Behav. 2013;41:34-41. https://doi.org/10.1177/1090198113485754.

21. Willoughby BJ, Carroll JS. The impact of living in co-ed resident halls on risk-taking among college students. J Am Coll Heal. 2009;58:241-6. https:// doi.org/10.1080/07448480903295359.

22. Fromme K, Corbin WR, Kruse MI. Behavioral risks during the transition from high school to college. Dev Psychol. 2008:44:1497-504. https://doi.org/10. 1037/a0012614.Behavioral.

23. Intituto Brasileiro de Geografia e Estatística. Pesquisa Nacional de Saúde do Escolar - PeNSE. 2017.

24. de Oliveira MM, Campos MO, de Andreazzi MAR, Malta DC, de Oliveira MM, Campos MO, et al. Characteristics of the National Adolescent School-based Health Survey - PeNSE. Brazil Epidemiol e Serviços Saúde. 2017;26:605-16. https://doi.org/10.5123/S1679-49742017000300017.

25. White MA. An Australian co-educational boarding school: a sociological study of Anglo-Australian and overseas students' attitudes from their own memoirs. Int Educ J. 2004;5:65-78.

26. Barros AJ, Hirakata VN. Alternatives for logistic regression in cross-sectional studies: an empirical comparison of models that directly estimate the prevalence ratio. BMC Med Res Methodol. 2003;3:21. https://doi.org/10.1186/ 1471-2288-3-21.

27. Sun GW, Shook TL, Kay G. Inappropriate use of bivariable analysis to screen risk factors for use in multivariable analysis. J Clin Epidemiol. 1996:49:907-16.

28. Harrell FE. Regression modeling strategies: with applications to linear models, logistic regression and survival analysis. New York: SpringerVerlag; 2001.

29. Küçük EE, Günay O. Health-related behaviors and nutritional status of adolescents who study as boarders and day-students. Turkish J Med Sci. 2016;46:960-6. https://doi.org/10.3906/sag-1503-3.

30. Momtazi S, Rawson RA. Substance abuse among Iranian high school students. Curr Opin Psychiatry. 2010;23:221-6. https://doi.org/10.1097/YCO. 0b013e328338630d.Substance.

31. Boulin A. O Internato Escolar : limites e paradoxos de uma instituição total. 985-1003.

32. Malta DC, Machado IE, Porto DL, da Silva MMA, de Freitas PC, da Costa $A W N$, et al. Alcohol consumption among Brazilian adolescents according to the National Adolescent School-based Health Survey (PeNSE 2012). Rev Bras Epidemiol. 2014;17:203-14. https://doi.org/10.1590/1809-4503201400050016.

33. Vendrame A, Pinsky I, Faria R, Silva R. Brazilian teenagers and beer advertising: relationship between exposure, positive response, and alcohol consumption. Cad Saude Publica. 2009:25:359-65. https://doi.org/10.1590/ S0102-311X2009000200014.
34. World Health Organization Department of Mental Health and Substance Dependence, Noncommunicable Diseases and Menyal Health Cluster. International Guide for monitoring alcohol consumption and related harm. 2000 p. 209.

35. Instituto Brasileiro de Geografia e Estatística. Pesquisa Nacional de Saúde do Escolar. Rio de Janeiro; 2013. p. 256.

36. Horta RL, de Mola CL, Horta BL, de Mattos CNB, de Andreazzi MAR, OliveiraCampos $\mathrm{M}$, et al. Prevalence and factors associated with illicit drug use throughout life: National School Health Survey 2015. Rev Bras Epidemiol. 2018;21. https://doi.org/10.1590/1980-549720180007.supl.1.

37. MacArthur GJ, Smith MC, Melotti R, Heron J, MacLeod J, Hickman M, et al. Patterns of alcohol use and multiple risk behaviour by gender during early and late adolescence: the ALSPAC cohort. J Public Health (Bangkok). 2012; 34:20-30. https://doi.org/10.1093/pubmed/fds006.

38. Oliveira-Campos M, Nunes ML, Madeira FDC, Santos MG, Bregmann SR, Malta DC, et al. Sexual behavior among Brazilian adolescents, National Adolescent School-based Health Survey (PeNSE 2012). Rev Bras Epidemiol. 2014;17:116-30. https://doi.org/10.1590/1809-4503201400050010.

39. Chang $C T$, Garg P, Giddon DB. Boarding school influence on self-reported concern for perceived body and face morphology in Taiwan. Asian J Psychiatr. Elsevier B.V.; 2016;22: 96-101. doi:https://doi.org/10.1016/j.ajp.2016. 05.008

\section{Publisher's Note}

Springer Nature remains neutral with regard to jurisdictional claims in published maps and institutional affiliations.
Ready to submit your research? Choose BMC and benefit from:

- fast, convenient online submission

- thorough peer review by experienced researchers in your field

- rapid publication on acceptance

- support for research data, including large and complex data types

- gold Open Access which fosters wider collaboration and increased citations

- maximum visibility for your research: over $100 \mathrm{M}$ website views per year

At $\mathrm{BMC}$, research is always in progress.

Learn more biomedcentral.com/submissions 